\title{
Mối quan hệ giữa hành vi đồng tạo sinh giá trị, sụ̣ hài lòng và lòng trung thành của khách hàng lĩnh vực $\mathrm{y}$ tế
}

\section{The relationship between customer value co-creation behavior, satisfaction and loyalty in healthcare industry}

\author{
Nguyễn Ngọc Duy Phương ${ }^{1 *}$, Lê Đình Minh Trí1 ${ }^{1}$ Võ Tường Huân ${ }^{1}$, \\ Trần Quốc Cường ${ }^{2}$, Trịnh Thị Thùy Dương ${ }^{2}$ \\ ${ }^{1}$ Trường Đại học Quốc tế - Đại học Quốc gia TP.HCM, Việt Nam \\ ${ }^{2}$ Bệnh viện Quận Thủ Đức, Việt Nam \\ *Tác giả liên hệ, Email: nndphuong@hcmiu.edu.vn
}

\section{THÔNG TIN}

DOI: 10.46223/HCMCOUJS. econ.vi.15.3.1329.2020

Ngày nhận: 12/05/2020

Ngày nhận lại: 29/05/2020

Duyệt đăng: 02/06/2020

Tù khóa:

hành vi đồng tạo sinh giá trị, sự hài lòng khách hàng, lòng trung thành, bệnh viện

Keywords:

value co-creation behavior, customer satisfaction, loyalty, hospital

\section{TÓM TĂT}




\section{Giới thiệu}

Trong thời kì hội nhập hiện nay, vai trò của ngành y tế trong việc đảm bảo sức khỏe cho người dân là vô cùng to lớn. Bất kì ai, dù giàu hay nghèo, đều quan tâm đến sức khỏe của bản thân vì có sức khỏe thì có thể làm nên mọi thứ. Ngày nay, do điều kiện sống và thu nhập bình quân đầu người đã cải thiện và tăng trưởng đáng kể, cho nên bệnh nhân chú ý nhiều hơn đến chất lượng dịch vụ khám chữa bệnh. Do đó, nâng cao sự hài lòng của bệnh nhân nhằm giữ chân các bệnh nhân cũ và thu hút thêm người bệnh mới là một yếu tố được đặt lên hàng đầu của tất cả các bệnh viện và các tổ chức khám, chữa bệnh khác. Đây chắc chắn sẽ là một thị trường cạnh tranh gay gắt giữa các bệnh viện trong việc chiếm được sự hài lòng của các bệnh nhân.

Y tế là ngành rất riêng biệt, liên quan trực tiếp đến sức khỏe, tính mạng của con người. Trong những năm qua, ngành y tế đã cải thiện một cách tích cực, nhắm đến nhiệm vụ cao cả nhất là tất cả vì sự nghiệp chăm sóc sức khỏe người dân và sự hài lòng của người bệnh. Từ ngày 01/10/2017, tất cả các bệnh viện công lập trực thuộc TP. HCM bắt đầu thực hiện cơ chế tự chủ hoàn toàn về tài chính, đây được cho là một bước ngoặt thay đổi quan trọng của ngành y tế nước ta. Các bệnh viện hiện nay đang chủ động cải tổ bộ máy hoạt động và đồng thời hiện đại hóa cơ sở vật chất, trang thiết bị y tế nhằm mục đích nâng cao chất lượng dịch vụ, ví dụ như: xây dựng, sửa chữa cơ sở hạ tầng khang trang, đầu tư mới và nâng cấp các trang thiết bị hiện đại, cải cách thủ tục hành chính, thay đổi tác phong làm việc, tập huấn và nâng cao kỹ năng giao tiếp của cán bộ nhân viên ngành y tế để gia tăng sự hài lòng của người bệnh và thân nhân người bệnh trong quá trình khám chữa bệnh tại cơ sở. Vì lí do đó, các bệnh viện công lập bắt buộc phải cải cách công tác quản lý, công tác xây dựng kế hoạch, thay đổi phương hướng hoạt động sao cho phù hợp với nhu cầu của bệnh nhân, nỗ lực trong việc nâng cao chất lượng khám chữa bệnh hướng tới sự hài lòng của người bệnh, để phát triển thương hiệu của chính họ và gia tăng năng lực cạnh tranh lành mạnh giữa các bệnh viện để giữ chân, làm người bệnh cảm thấy hài lòng và tiếp tục chọn cơ sở trong những lần khám, chữa bệnh tiếp theo.

Sự hài lòng, lòng trung thành của người bệnh trong lĩnh vực y tế là một trong những chủ đề được nhiều nhà nghiên cứu quan tâm và tìm hiểu. Nhiều nghiên cứu đã được tiến hành để tìm hiểu về định nghĩa, cấu trúc, sự tác động cũng như các yếu tố ảnh hưởng đến mức độ hài lòng và lòng trung thành của bệnh nhân như: nghiên cứu bối cảnh nước ngoài của Lee, Lee, và Kang (2012), Astuti và Nagase (2016) và các nhà nghiên cứu trong nước cũng đã quan tâm đến vấn đề này như nghiên cứu trong nước của Tran (2014), H. T. M. Nguyen (2014), T. T. Le (2017), Huynh (2018). Hầu hết các nghiên cứu tại Việt Nam đều đã cho thấy mối quan hệ giữa nhân tố chất lượng dịch vụ y tế của bệnh viện và sự hài lòng, lòng trung thành của bệnh nhân đối với cơ sở khám, chữa bệnh. Hơn thế nữa, nhiệm vụ quản lý chất lượng dịch vụ của các bệnh viện để nâng cao sự hài lòng, lòng trung thành của bệnh nhân đều do bệnh viện chủ động phụ trách với trách nhiệm là bên cung cấp dịch vụ. Các cấp lãnh đạo ngành y tế chưa nhìn ra được vai trò tham gia và đóng góp của chính khách hàng/người bệnh của mình trong quá trình khám bệnh, chữa bệnh thông qua hành vi tham gia để tạo nên giá trị dịch vụ với bệnh viện. Thực tế trên thế giới đã chứng minh đồng tạo sinh là việc khách hàng cùng với cơ sở khám, chữa bệnh cùng đóng góp trong quá trình cung cấp dịch vụ để tạo ra dịch vụ chăm sóc tốt hơn nhằm mục đích nâng cao giá trị cảm nhận cho khách hàng (Grönroos \& Voima, 2013; Vargo \& Lusch, 2008). Các nhà nghiên cứu Roser, Samson, Humphreys, và Cruz-Valdivieso (2009) giải thích rằng đồng tạo sinh giá trị đạt được khi khách hàng có vai trò chủ động liên kết với bên cung cấp dịch vụ. Liên kết giúp khách hàng là người đồng tạo hiệu quả trong việc đạt được kết quả thành công của dịch vụ. Có thể nói rằng, đồng tạo sinh giá trị được thực hiện thông qua sự liên kết giữa bên cung cấp dịch vụ và khách hàng bằng việc sử dụng nguồn lực kết hợp (Grönroos \& Voima, 2013; Sweeney, Danaher, \& McCollKennedy, 2015). 
Đồng tạo sinh giá trị là yếu tố cần thiết trong lĩnh vực y tế vì yêu cầu sự tham gia của nhiều bên liên quan trong quá trình phục vụ bệnh nhân (Carrubbo, Bruni, Cavacece, \& Tartaglione, 2015). Hiện nay, các bệnh nhân tại các bệnh viện thường tham gia vào quá trinh khám, chữa bệnh theo sự hướng dẫn của bác sĩ điều trị để ghi nhận tình trạng sức khỏe hằng ngày. Sự hỗ trợ của bệnh nhân là phần thiết yếu để đồng tạo sinh giá trị đạt được thành công từ 2 phía thông qua phương thức trao đổi kiến thức và kỹ năng (Lee, 2017). Trong nghiên cứu của Eldh, Ekman, và Ehnfors (2006) cho rằng bệnh nhân sẽ hỗ trợ tích cực hơn khi họ có quyền được đưa ra ý kiến liên quan đến các phương án điều trị và quyết định việc lựa chọn chữa trị. Nếu bệnh nhân cảm thấy hứng thú về việc hỗ trợ và hài lòng với vai trò của mình thì sẽ sẳn sàng tương tác với nhân viên $\mathrm{y}$ tế để đạt được kết quả điều trị tốt (Yi \& Gong, 2013). Tương tự, Bitner, Faranda, Hubbert, và Zeithaml (1997) đã mô tả các vai trò khác nhau của bệnh nhân trong việc chăm sóc sức khoẻ, sự tham gia của người bệnh đã tạo ra sự hỗ trợ hiệu quả và đóng góp đáng kể vào chất lượng dịch vụ, sự hài lòng và giá trị của chính họ. Tình trạng tâm lý, sức khỏe và sự hài lòng của bệnh nhân đối với bác sĩ được cải thiện đáng kể nhờ vào sự tham gia của họ trong quá trình điều trị thông qua hình thức chia sẻ thông tin để cùng đưa ra quyết định (Bottorff et al., 1998; Rafii, Soleimani, \& Seyed-Fatemi, 2010; Tutton, 2005). Nắm rõ được bệnh nhân phải tham gia như thế nào trong quá trình điều trị để đạt kết quả điều trị và chăm sóc sức khỏe tốt hơn là điều quan trọng không chỉ đối với cá nhân họ mà còn quan trọng đối với các bệnh viện và cơ quan quản lý nhà nước.

Để đánh giá, nghiên cứu một cách nghiêm túc và khoa học, nhằm làm tăng thêm hành vi tham gia của bệnh nhân trong quá trình khám chữa bệnh, qua đó làm bệnh nhân thêm hài lòng hơn khi khám, chữa bệnh; đồng thời giữ chân và thu hút thêm bệnh nhân trở thanh mục tiêu thiết thực. Bên cạnh đó, bệnh viện Quận Thủ Đức là bệnh viện được xếp hạng là bệnh viện tuyến quận, huyện hạng I đầu tiên trên cả nước, có điểm số đứng đầu trong khối bệnh viện quận, huyện tại Thành phố Hồ Chí Minh dựa trên kết quả kiểm tra chất lượng của các bệnh viện hàng năm. Bên cạnh đó, Bệnh viện Quận Thủ Đức còn là nơi đăng ký khám chữa bệnh ban đầu, được thực hiện chính sách thông tuyến bảo hiểm y tế trên toàn quốc. Vì vậy, Bệnh viện không chỉ khám chữa bệnh, chăm sóc sức khỏe cho người dân tại địa bàn Thành phố Hồ Chí Minh mà còn tiếp nhận lượng người dân trên các tỉnh, thành khác như Bình Dương, Đồng Nai, các tỉnh Miền Tây và một số tỉnh lân cận. Do đó, nghiên cứu thực hiện tại Bệnh viện Quận Thủ Đức sẽ không bị hạn chế về đối tượng bệnh và các mặt bệnh rất đa dạng, do đó thể hiện được tính khái quát giữa các đối tượng nghiên cứu.

\section{Cơ sở lý thuyết và mô hình nghiên cứu}

\subsection{Khái niệm hành vi đồng tạo sinh giá trị}

Tuy rằng sự tham gia của khách hàng trong quá trình đáp ứng dịch vụ đã được áp dụng nhiều trong các ngành dịch vụ (Chuang \& Chen, 2015; Delpechitre, Connelly, \& Chaker, 2018; Tommasetti, Troisi, \& Vesci, 2017; Vega-Vazquez, Revilla-Camacho, \& Cossío-Silva, 2015) nhưng trong ngành y tế nói chung và đặc biệt là $Y$ tế Việt Nam nói riêng thì sự tham gia này chưa được áp dụng phổ biến. Hành vi đồng tạo sinh giá trị (hành vi tham gia của người bệnh) là một thành phần quan trọng trong việc thiết kế lại các quy trình chăm sóc sức khỏe và áp dụng thành công vào một số khía cạnh của chăm sóc người bệnh ở lĩnh vực y tế. Sự tham gia của người bệnh ngày càng tăng đã được khuyến nghị để gia tăng tính an toàn cho bệnh nhân (Allegranzi et al., 2007). Một quan điểm cho rằng hành vi tham gia vào các quyết định điều trị được đưa ra về các vấn đề sức khỏe của chính người bệnh (Thompson, 2007). Ở một góc nhìn khác, sự tham gia của bệnh nhân có nghĩa là tham gia trong việc chia sẻ thông tin, cảm xúc và làm theo chỉ dẫn của cán bộ y tế (Rafii et al., 2010). Hành vi tham gia của bệnh nhân trong việc ra quyết định điều trị hoặc bày tỏ ý kiến về các phương án điều trị khác nhau, bao gồm chia sẻ thông tin, cảm xúc, dấu hiệu và chấp nhận hướng dẫn của đội ngũ y tế. 
Theo tìm hiểu của tác giả thì nghiên cứu của Yi và Gong (2013) đã nghiên cứu và đề xuất thang đo hành vi đồng tạo giá trị của khách hàng thông qua nghiên cứu thực nghiệm. Kết quả thu được đã chứng minh tính thực tiễn và phù hợp của thang đo. Bên cạnh đó, nhiều nghiên cứu khác có liên quan đến sự tham gia của khách hàng cũng đã sử dụng thang đo của Yi và Gong (2013) trong các ngành dịch vụ bao gồm cả dịch vụ y tế như: nghiên cứu của Revilla-Camacho, VegaVázquez, và Cossío-Silva (2015) tìm hiểu về sự ảnh hưởng của hành vi tham gia và hành vi công dân của khách hàng trong việc thực hiện dịch vụ đến doanh thu; nghiên cứu của $\mathrm{H}$. N. Le (2016) về tác động của sự tham gia của bệnh nhân ảnh hưởng đến sự hài lòng của bệnh nhân thông qua giá trị cảm nhận trong ngành y khoa; nghiên cứu của Huynh (2018) về mức độ ảnh hưởng của hành vi đồng tạo giá trị và sự hài lòng, lòng trung thành của bệnh nhân. Từ các nghiên cứu trên, tác giả đề nghị sử dụng thang đo kết hợp để đánh giá hành vi tham gia của bệnh nhân: một phần sẽ trích từ thang đo hành vi đồng tạo giá trị của Yi và Gong (2013) và phần còn lại trích từ thang đo của Huynh (2018). Đồng thời, xác định các nhân tố của hành vi tham gia của bệnh nhân trong lĩnh vực y tế bao gồm: hành vi tìm kiếm thông tin, hành vi chia sẻ thông tin, hành vi trách nhiệm và tương tác cá nhân, cụ thể:

(1) Hành vi tìm kiếm thông tin là toàn bộ hành động của khách hàng trong việc tìm kiếm thông tin để làm rõ yêu cầu dịch vụ và đáp ứng các nhu cầu nhận thức khác (Yi \& Gong, 2013). Khách hàng phải có quyền truy cập vào các thông tin liên quan đến các phần chủ yếu của dịch vụ mà họ sẽ nhận được. Kiến thức này sẽ tạo điều kiện cho sự tham gia của khách hàng trong quá trình đồng tạo ra giá trị.

(2) Hành vi chia sẻ thông tin là hành động của người bệnh chia sẻ thông tin với các nhà cung cấp dịch vụ chăm sóc sức khỏe thông qua các hành vi như mô tả tình trạng và triệu chứng hiện tại của họ, chia sẻ thông tin về lịch sử và cách điều trị bệnh và bày tỏ muốn theo đuổi các liệu pháp và quy trình cụ thể (Gallan, Jarvis, Brown, \& Bitner, 2013). Tuy nhiên, không phải tất cả bệnh nhân thực hành hành vi này ở cùng một mức độ. Khi được hỏi, một số người trong số họ có thể không chuẩn bị để cung cấp tất cả thông tin cần thiết cho bác sĩ. Điều này có thể là do kiến thức hạn chế hoặc cảm xúc tiêu cực dẫn đến việc chia sẻ thông tin không diễn ra hoặc không chính xác. Do đó, có sự khác biệt trong phạm vi của hành vi tham gia này giữa các bệnh nhân. Yi và Gong (2013) nhấn mạnh rằng nếu khách hàng không chia sẻ thông tin phù hợp, kết quả của dịch vụ có thể không được như mong đợi.

(3) Hành vi có trách nhiệm đề cập đến các hoạt động hợp tác của khách hàng được yêu cầu trong sử dụng dịch vụ (Yi \& Gong, 2013). Trong lĩnh vực y tế, hành vi có trách nhiệm thể hiện trong việc hợp tác với các nỗ lực chẩn đoán của bác sĩ (Gallan et al., 2013).

(4) Tương tác cá nhân liên quan đến mối quan hệ giữa các khách hàng và nhân viên, điều này là thiết yếu cho sự thành công của việc đồng tạo giá trị (Yi \& Gong, 2013). Sự gắn kết mối quan hệ cá nhân giữa khách hàng và nhân viên dựa trên sự lịch sự, thân thiện và tôn trọng là đặc điểm thiết yếu cho sự thành công của quá trình đồng tạo ra giá trị.

\subsection{Khái niệm sụ hài lòng của người bệnh}

Có nhiều khái niệm khác nhau về sự hài lòng của khách hàng cũng như có khá nhiều tranh luận về định nghĩa này. Nhiều nhà nghiên cứu cho rằng sự hài lòng là sự khác biệt giữa kì vọng của khách hàng và cảm nhận thực tế nhận được (Fornell, Johnson, Anderson, Cha, \& Bryant, 1996). Sự hài lòng của khách hàng là cảm nhận tổng quan của khách hàng đối với một nhà cung cấp dịch vụ, hoặc một cảm xúc phản ứng lại với sự khác biệt giữa những gì khách hàng mong muốn và những gì họ thực sự cảm nhận được, đối với sự đáp ứng một số nhu cầu, mục tiêu hay mong muốn (Hansemark \& Albinsson, 2004). Đối với sự hài lòng của bệnh nhân, đến nay vẫn có 
nhiều quan điểm khác nhau. Sự hài lòng của bệnh nhân được thể hiện qua quan hệ của người bệnh đối với y bác sĩ và đội ngũ chăm sóc sức khỏe (Zyzanski, Hulka, \& Cassel, 1974). Một số nhà nghiên cứu khác như Mohan và Kumar (2011) lại nghiên cứu hài lòng bệnh nhân từ góc độ cảm xúc, cảm nghĩ và nhận thức của người bệnh đối với dịch vụ đã sử dụng ở cơ sở khám chữa bệnh. Bên cạnh đó, nhiều nhà nghiên cứu cho rằng sự hài lòng của bệnh nhân là mức độ tương đồng giữa kỳ vọng của bệnh nhân đối với dịch vụ khám, chữa bệnh lý tưởng và kết quả thực tế bệnh nhân nhận được (Singh, 1989). Ở Việt Nam, cách thức tiếp cận của Bộ Y tế đối với khảo sát sự hài lòng của bệnh nhân dựa trên khái niệm này, và nghiên cứu của tác giả cũng sử dụng quan điểm trên.

\subsection{Khái niệm lòng trung thành của người bệnh}

Lòng trung thành của khách hàng là một trong những tài sản vô hình có giá trị nhất mà một tổ chức có thể sở hữu, lòng trung thành được thể hiện qua hành vi và thái độ của khách hàng chính là lợi thế cạnh tranh quan trọng của các công ty, tập đoàn (Cossío-Silva, Revilla-Camacho, VegaVázquez, \& Palacios-Florencio, 2016). Người tiêu dùng quay lại nhiều lần để mua dịch vụ từ cùng một công ty được xem là một khách hàng trung thành ty (Bitner, 1990; Ennew \& Binks, 1996). Chahal (2008) lập luận rằng lòng trung thành của bệnh nhân có thể được đo lường trên ba thành phần đó là: sử dụng lại các nhà cung cấp cho cùng một điều trị, sử dụng lại các nhà cung cấp cho các phương pháp điều trị khác nhau và giới thiệu các nhà cung cấp cho những người khác. Thực tế ngành y tế của nước ta trong giai đoạn hiện nay thì sự hoạt động và duy trì của các bệnh viện phụ thuộc chính vào sự tin tưởng và lựa chọn của bệnh nhân. Với chính sách cho phép thông tuyến khám chữa bệnh theo chế độ của bảo hiểm y tế thì sự lựa chọn cơ sở khám chữa bệnh của người dân sẽ không còn bị hạn chế theo vùng, miền, khu vực hay vị trí địa lý nói chung mà người dân có quyền tự do lựa chọn nơi khám và điều trị phù hợp theo ý muốn của cá nhân. Khi đó, chính lòng trung thành của bệnh nhân mà các bệnh viện vun đắp được sẽ là tài sản quý báu, là nhân tố thiết yếu tạo nên lợi thế cạnh tranh, đảm bảo sự phát triển và vững mạnh của các bệnh viện. Nghiên cứu này đánh giá lòng trung thành của bệnh nhân ở cả hai vấn đề: lòng trung thành về hành vi và lòng trung thành về thái độ. Cụ thể hơn nữa, lòng trung thành của bệnh nhân thể hiện qua sự tin tưởng, hành động ưu tiên lựa chọn và lặp lại vào các lần sau, đồng thời kết hợp với truyền miệng tích cực và khuyến nghị người quen lựa chọn sử dụng dịch vụ khám bệnh, chữa bệnh tại cùng một bệnh viện.

\subsection{Giả thuyết và mô hình nghiên cứu}

Trong thị trường mở cửa và tự do cạnh tranh hiện nay thì điều cần thiết đối với sự vững mạnh và phát triển thành công của một công ty chính là xây dựng và giữ được mối quan hệ tốt đẹp với khách hàng của mình, và cách tốt nhất để đạt được điều đó chính là luôn lắng nghe và đáp ứng nhu cầu của khách hàng, đồng thời làm tăng sự tin tưởng của khách hàng dành cho tổ chức (Lee et al., 2012). Nghiên cứu của Gallan và cộng sự (2013) đã xây dựng mô hình lý thuyết nghiên cứu để đánh giá theo kinh nghiệm tình cảm cụ thể và sự tham gia của khách hàng trong quá trình trải nghiệm dịch vụ chăm sóc sức khoẻ ảnh hưởng đến nhận thức của nhà cung cấp dịch vụ. Kết quả nghiên cứu cho thấy sự tham gia của khách hàng và chất lượng dịch vụ là chất trung gian, có ảnh hưởng tích cực đối với sự hài lòng của khách hàng. H. N. Le (2016) đã phát hiện ra tác động của các hành động gặp gỡ dịch vụ và sự tham gia của khách hàng vào quá trình tương tác để tạo ra giá trị, dẫn đến sự hài lòng của khách hàng. Nghiên cứu của Chen và Wang (2016) đã khẳng định sự tham gia của khách hàng có liên quan tích cực đến cả ba giá trị (giá trị hưởng thụ, giá trị kinh tế và giá trị quan hệ), điều này dẫn đến sự hài lòng của khách hàng đối với toàn hệ thống; sự hài lòng của hệ thống cũng ảnh hưởng đến sự hài lòng của khách hàng đối với công ty và cả sự hài lòng của khách hàng đối với hệ thống và công ty đều có tác động tích cực đến lòng trung thành của khách hàng. Các giá trị mà khách hàng cảm nhận được thông qua sự tham gia của chính họ ảnh hưởng tích cực đến sự hài lòng đối với hệ thống cũng như công ty và do đó có tác động đến lòng 
trung thành của những khách hàng đó. Dựa trên cơ sở lý thuyết về các khái niệm nghiên cứu và khảo sát sơ lượt về lý thuyết của các nghiên cứu có liên quan, có thể nhận thấy rằng hành vi tham gia của bệnh nhân tác động tích cực đến sự hài lòng và lòng trung thành của bệnh nhân. Từ đó, nghiên cứu đề xuất giả thuyết $\mathrm{H} 1$ và $\mathrm{H} 2$ như sau:

\section{$H_{1}$ : Hành vi tham gia của bệnh nhân tác động tích cực đến sụ hài lòng của bệnh nhân}

$\mathrm{H}_{2}$ : Hành vi tham gia của bệnh nhân tác động tích cực đến lòng trung thành của bệnh nhân

Có rất nhiều nghiên cứu đã khẳng định mối quan hệ giữa sự hài lòng và lòng trung thành của khách hàng. Sự hài lòng không những làm giảm việc khiếu nại mà còn gia tăng lòng trung thành của khách hàng (Reichheld \& Sasser, 1990), làm tăng ý định mua lặp lại (Gotlieb, Grewal, \& Brown, 1994), mang lại hiệu quả tài chính tốt hơn (Fornell, 1992). Khách hàng có sự hài lòng cao thì càng có nhiều khả năng mua hàng hoá và dịch vụ được cung cấp bởi cùng một tổ chức (Gronholdt, Martensen, \& Kristensen, 2000). Nghiên cứu của Astuti và Nagase (2016) đã hình thành và phát triển một khung nghiên cứu về định nghĩa lòng trung thành của bệnh nhân đối với các tổ chức chăm sóc sức khoẻ, mối quan hệ giữa lòng trung thành và sự hài lòng của bệnh nhân với một số yếu tố khác như sự chuyển đổi nhà cung cấp, mối quan hệ. Tương tự, nghiên cứu của Platonova, Kennedy, và Shewchuk (2008) đã tìm ra sự tác động tích cực của sự hài lòng của bệnh nhân tới lòng trung thành họ đối với dịch vụ chăm sóc sức khỏe. Đã có một số nghiên cứu lấy bối cảnh trong nước về ảnh hưởng của giá trị cảm nhận đến sự hài lòng và lòng trung thành của khách hàng đối với dịch vụ khám chữa bệnh của các bệnh viện tại TP. HCM (Lam, 2017; H. T. M. Nguyen, 2014; Tran, 2014). Kết quả của các nghiên cứu đều đã khẳng định sự hài lòng có tác động tích cực một cách đáng kể đến lòng trung thành của bệnh nhân. Do đó, sự hài lòng được xem là một thành phần ảnh hưởng chính đến lòng trung thành của khách hàng. Đo lường mức độ hài lòng của khách hàng là rất quan trọng, đặc biệt trong ngành y tế (Friesner, Neufelder, Raisor, \& Bozman, 2009). Bệnh viện nỗ lực làm gia tăng sự hài lòng của bệnh nhân, qua đó giữ vững và phát triển số lượng bệnh nhân trung thành vì bệnh nhân hài lòng với dịch vụ, khám chữa bệnh của bệnh viện thì có xu hướng tái sử dụng (xem lại hoặc mua lại). Qua đó, nghiên cứu đề xuất giả thuyết như sau:

\section{$H_{3}$ : Sự hài lòng của bệnh nhân tác động tích cực đến lòng trung thành của bệnh nhân}

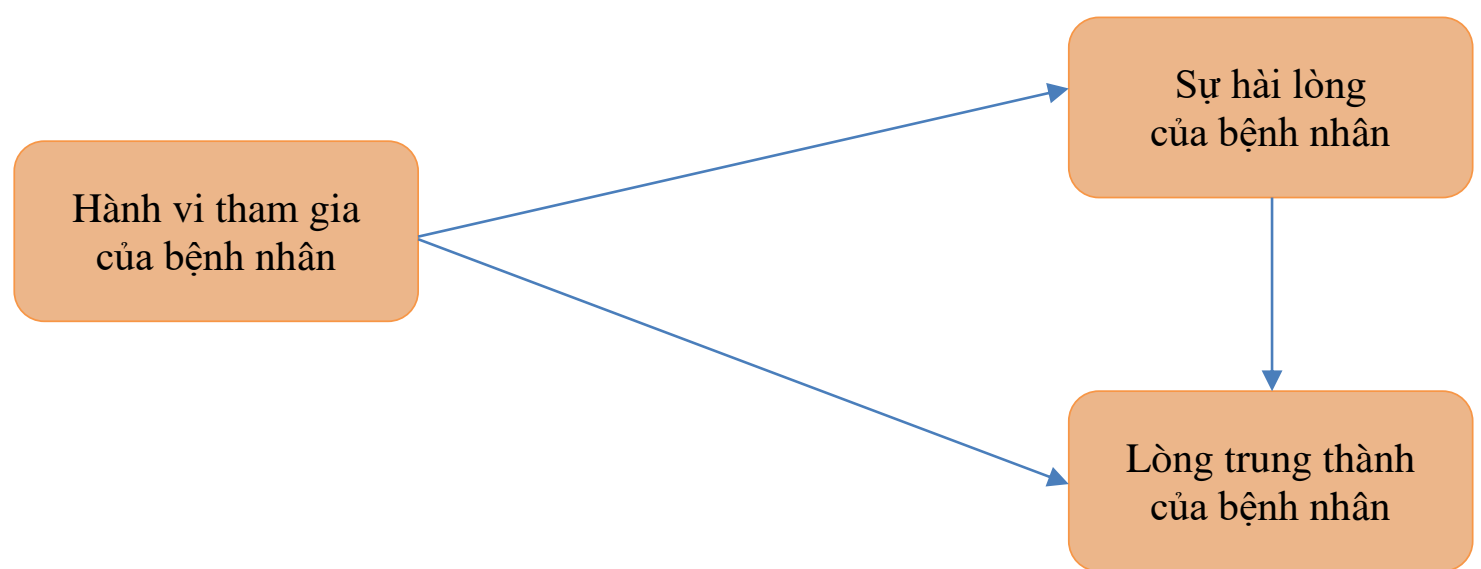

Hình 1. Mô hình nghiên cứu đề xuất

\section{Phương pháp nghiên cứu}

Nghiên cứu này sử dụng phương pháp nghiên cứu định lượng. Quy trình thực hiện thông qua các bước khảo cứu các khái niệm, các nghiên cứu liên quan để xây dựng mô hình nghiên cứu. Sau đó, tham khảo và kế thừa các bộ công cụ từ những nghiên cứu trước để đề xuất thang đo sơ 
bộ. Thang đo yếu tố hành vi đồng tạo sinh giá trị của bệnh nhân gồm 14 biến được hiệu chỉnh từ thang đo của Yi và Gong (2013) và Huynh (2018); thang đo sự hài lòng của người bệnh gồm 4 biến được kế thừa từ Tran (2014) và $\mathrm{T}$. T. Le (2017); và thang đo lòng trung thành của người bệnh gồm 4 biến dựa theo Tran (2014), H. T. M. Nguyen (2014) và Lam (2017). Sau đó, tiến hành nghiên cứu định tính để điều chỉnh thang đo và đưa ra thang đo chính thức. Phỏng vấn trực tiếp 3 chuyên gia quản lý y tế, bao gồm trưởng đơn vị nghiên cứu khoa học, trưởng phòng chăm sóc khách hàng và trưởng phòng quản lý chất lượng của bệnh viện Thủ Đức. Sau khi điều chỉnh theo ý kiến của các chuyên gia, thang đo về hành vi tham gia sử dụng cho nghiên cứu định lượng gồm 15 biến quan sát cụ thể như sau: hành vi tìm kiếm thông tin tăng 1 biến, hành vi chia sẻ thông tin giảm 1 biến do gộp 2 biến, hành vi trách nhiệm tăng 1 biến và hành vi giao tiếp giữ nguyên 3 biến. Các chuyên gia đồng ý giữ nguyên 2 thang đo về sự hài lòng và lòng trung thành của bệnh nhân. Đồng thời, để đảm bảo tính rõ ràng và dễ hiểu cho đối tượng khảo sát, nghiên cứu phỏng vấn thử 20 người khám chữa bệnh ngoại trú tại các phòng khám của bệnh viện. Người bệnh tham gia khảo sát được hỏi về mức độ dễ hiểu và rõ ràng của các câu hỏi, sau đó cho nhận xét về tính phù hợp của các câu hỏi so với trải nghiệm cũng như hành vi trong thực tế của bản thân bệnh nhân. Kết quả là tất cả các thang đo đều đảm bảo độ tin cậy để tiến hành khảo sát chính thức. Quy trình khảo sát, tác giả tổ chức tập huấn, hướng dẫn cho các điều tra viên, về cách thu thập thông tin. Trước khi tiến hành điều tra, đối tượng phỏng vấn được điều tra viên giải thích rõ về mục đích, ý nghĩa của việc khảo sát, xin ý kiến đồng ý tham gia nghiên cứu thì phỏng vấn và hướng dẫn cho đối tượng nghiên cứu có thể tự trả lời. Người bệnh được các điều tra viên phỏng vấn trực tiếp bằng bảng câu hỏi được thiết kế sẵn tại các phòng khám của bệnh viện Quận Thủ Đức. Sau khi hoàn thành xong bảng hỏi bằng cách điền trực tiếp câu trả lời vào bảng hỏi, người bệnh trả lại cho điều tra viên. Tính đến thời điểm nghiên cứu, có 420 người tham gia nghiên cứu, tuy nhiên số phiếu hợp lệ chỉ đạt được 405 phiếu, tỷ lệ đạt được là 96,4\%. Có 4,6\% số phiếu không hợp lệ với lý do người bệnh tham gia không hết cuộc phỏng vấn, người bệnh tự trả lời trong bảng câu hỏi không đầy đủ. Phân tích xử lý số liệu sử dụng công cụ SPSS 20.0 và AMOS 21.0. với các kỹ thuật thống kê mô tả dữ liệu, đánh giá độ tin cậy thang đo, phân tích nhân tố khám phá, phân tích nhân tố khẳng định, phân tích mô hình cấu trúc tuyến tính SEM, kiểm tra mối quan hệ giữa các biến và kiểm tra ước lượng mô hình bằng phương pháp Bootstrap (T. D. Nguyen \& Nguyen, 2011).

\section{Kết luận}

\subsection{Thống kê mô tả}

Kết quả về mẫu dữ liệu thu thập được cho thấy về giới tính, tỷ lệ mẫu khảo sát theo giới tính bệnh nhân là nữ cao hơn, chiếm $58 \%$. Về địa điểm sinh sống, tỷ lệ bệnh nhân cư trú ở các tỉnh, thành khác là $39,5 \%$ trong khi tỷ lệ bệnh nhân cư trú ở TP. HCM là $60.5 \%$. Về nhóm tuổi, nhóm bệnh nhân có độ tuổi từ 18-30 tuổi chiếm tỷ lệ nhiều nhất (tỷ lệ 38\%). Tiếp đến là nhóm 31 - 50 tuổi chiếm $32,4 \%$, và thấp nhất là nhóm trên 50 tuổi với $29,6 \%$. Hầu hết bệnh nhân đều sử dụng thẻ BHYT khi đăng ký sử dụng dịch vụ y tế, thống kê thể hiện trên 2/3 (84,9\%) bệnh nhân đều tham gia bảo hiểm y tế, chỉ có $15,1 \%$ là không tham gia. Lý do chủ yếu mà bệnh nhân lựa chọn bệnh viện để điều trị là do đăng ký BHYT ban đầu tại bệnh viện với $46,4 \%$, tiếp đến là bản thân/người thân đã từng điều trị chiếm tỷ lệ $28,6 \%$, bạn bè giới thiệu là $8,9 \%$ và thấp nhất là từ cơ sở $\mathrm{y}$ tế khác chuyển đến chiếm $3,1 \%$.

Người trả lời phỏng vấn đánh giá khá cao về hành vi trách nhiệm trong nhóm hành vi tham gia của người bệnh (3.76). Hành vi giao tiếp cũng được đánh giá khá tốt (3.70), kế đến là hành vi chia sẻ thông tin (3.64) và cuối cùng là hành vi tìm kiếm thông tin (3.60). Bệnh nhân cũng khá hài lòng với việc khám chữa bệnh (3.62), trong đó HL4 cho rằng quyết định khám chữa bệnh tại bệnh viện là đúng đắn được đánh giá cao nhất. Đồng thời, bệnh nhân cũng thể hiện lòng trung thành với 
bệnh việc cao nhất (3.94) với biến quan sát TT4 chỉ lựa chọn BV này khi có nhu cầu khám chữa bệnh được đánh giá rất cao.

\subsection{Phân tích độ tin cậy thang đo}

Nghiên cứu phân tích độ tin cậy thang đo bằng hệ số Cronbach's Alpha cho từng thang đo thành phần của hành vi đồng tạo sinh giá trị, thang đo sự hài lòng và lòng trung thành của bệnh nhân. Kết quả phân tích cho thấy tất cả các thang đo thành phần của hành vi đồng tạo sinh giá trị đều đảm bảo độ tin cậy với hệ số Cronbach's Alpha dao động từ $0.829-0.876$. Tất cả hệ số tương quan giữa biến thành phần và biến tổng đều lớn hơn 0.3 . Độ tin cậy của thang đo sự hài lòng và lòng trung thành của người bệnh đều đảm bảo lần lược là 0.866 và 0.889 . Kết quả phân tích độ tin cậy thang đo cụ thể như sau:

\section{Bảng 1}

Kết quả phân tích độ tin cậy thang đo

\begin{tabular}{|c|c|c|c|c|}
\hline Thang đo/Hệ số Cronbach's Alpha của thang đo & Mã hóa & $\begin{array}{l}\text { Phương } \\
\text { sai thang } \\
\text { đo nếu } \\
\text { loại biến }\end{array}$ & $\begin{array}{l}\text { Tương } \\
\text { quan } \\
\text { biến } \\
\text { tổng }\end{array}$ & $\begin{array}{l}\text { Hệ số } \\
\text { (CA) } \\
\text { nếu loại } \\
\text { biến }\end{array}$ \\
\hline \multicolumn{5}{|l|}{ Hành động tìm kiếm thông tin $(\alpha=0.867)$} \\
\hline $\begin{array}{l}\text { Ông/Bà hỏi mọi người quen biết các thông tin về bệnh } \\
\text { viện }\end{array}$ & TKTT1 & 6,360 & 0,719 & 0,830 \\
\hline Ông/Bà tìm kiếm thông tin về vị trí của bệnh viện & TKTT2 & 6,475 & 0,704 & 0,836 \\
\hline $\begin{array}{l}\text { Ông/Bà chú ý cách đăng kí khám bệnh và thông tin về } \\
\text { các dịch vụ của bệnh viện từ những người bệnh khác }\end{array}$ & TKTT3 & 6,394 & 0,718 & 0,830 \\
\hline $\begin{array}{l}\text { Ông/Bà có thường xuyên tìm hiểu thông tin của bệnh } \\
\text { viện trên website và mạng xã hội }\end{array}$ & TKTT4 & 7,437 & 0,765 & 0,824 \\
\hline \multicolumn{5}{|l|}{ Hành vi chia sẻ thông tin $(\alpha=0.829)$} \\
\hline $\begin{array}{l}\text { Ông/Bà nói rõ những dấu hiệu, triệu chứng cho nhân } \\
\text { viên tiếp đón (nhân viên đăng ký) }\end{array}$ & CSTT1 & 3,482 & 0,685 & 0,766 \\
\hline $\begin{array}{l}\text { Ông/Bà đã trình bày đầy đủ về tình trạng bệnh tật, các } \\
\text { triệu chứng và lịch sử bệnh của mình cho nhân viên y } \\
\text { tế }\end{array}$ & CSTT2 & 3,479 & 0,731 & 0,719 \\
\hline $\begin{array}{l}\text { Ông/Bà trả lời đầy đủ các câu hỏi của bác sĩ để họ có } \\
\text { thể chẩn đoán và điều trị chính xác }\end{array}$ & CSTT3 & 3,706 & 0,647 & 0,803 \\
\hline \multicolumn{5}{|l|}{ Hành vi có trách nhiệm $(\alpha=0.864)$} \\
\hline $\begin{array}{l}\text { Ông/Bà thực hiện tất cả các yêu cầu của bác sĩ, điều } \\
\text { dưỡng }\end{array}$ & HVTN1 & 9,545 & 0,762 & 0,814 \\
\hline $\begin{array}{l}\text { Ông/Bà tuân thủ đúng và đầy đủ các lời khuyên của } \\
\text { bác sĩ/điều dưỡng (chế độ ăn uống, những điều cần } \\
\text { tránh) }\end{array}$ & HVTN2 & 11,089 & 0,634 & 0,847 \\
\hline $\begin{array}{l}\text { Ông/Bà chủ động theo dõi các giai đoạn của quá trình } \\
\text { điều trị }\end{array}$ & HVTN3 & 10,859 & 0,644 & 0,844 \\
\hline
\end{tabular}




\begin{tabular}{|c|c|c|c|c|}
\hline Thang đo/Hệ số Cronbach's Alpha của thang đo & Mã hóa & $\begin{array}{c}\text { Phương } \\
\text { sai thang } \\
\text { đo nếu } \\
\text { loại biến }\end{array}$ & $\begin{array}{c}\text { Tương } \\
\text { quan } \\
\text { biến } \\
\text { tổng }\end{array}$ & $\begin{array}{c}\text { Hệ số } \\
\text { (CA) } \\
\text { nếu loại } \\
\text { biến }\end{array}$ \\
\hline $\begin{array}{l}\text { Ông/Bà chấp hành và yêu cầu người nhà của mình } \\
\text { chấp hành nội quy của bệnh viện/Khoa điều trị }\end{array}$ & HVTN4 & 11,148 & 0,617 & 0,851 \\
\hline Ông/Bà sẵn sàng thanh toán chi phí khám chữa bệnh & HVTN5 & 9,693 & 0,765 & 0,813 \\
\hline \multicolumn{5}{|l|}{ Hành vi giao tiếp $(\alpha=0.876)$} \\
\hline Ông/Bà cư xử lịch sự, tử tế với bác sĩ, điều dưỡng & HVGT1 & 3,624 & 0,758 & 0,829 \\
\hline Ông/Bà thể hiện sự tôn trọng với nhân viên y tế & HVGT2 & 3,707 & 0,755 & 0,831 \\
\hline Ông/Bà đã không cư xử thô lỗ với nhân viên y tế & HVGT3 & 3,632 & 0,772 & 0,816 \\
\hline \multicolumn{5}{|l|}{ Sự hài lòng của người bệnh ( $\alpha=0.866)$} \\
\hline Ông/Bà hài lòng khi khám chữa bệnh tại bệnh viện & HL1 & 8,089 & 0,744 & 0,818 \\
\hline $\begin{array}{l}\text { Mong đợi của Ông/Bà về dịch vụ khám chữa bệnh do } \\
\text { bệnh viện cung câp đã được đáp ứng }\end{array}$ & HL2 & 8,184 & 0,687 & 0,841 \\
\hline $\begin{array}{l}\text { Ông/bà hài lòng với bệnh viện này hơn những bệnh } \\
\text { viện khác }\end{array}$ & HL3 & 8,420 & 0,672 & 0,847 \\
\hline $\begin{array}{l}\text { Ông/Bà cho rằng quyết định khám chữa bệnh tại bệnh } \\
\text { viện là đúng đắn }\end{array}$ & HL4 & 8,008 & 0,763 & 0,810 \\
\hline \multicolumn{5}{|l|}{ Lòng trung thành của người bệnh $(\alpha=0.889)$} \\
\hline $\begin{array}{l}\text { Ông/Bà nghĩ đến bệnh viện này đầu tiên khi có nhu } \\
\text { cầu khám chữa bệnh }\end{array}$ & TT1 & 6,509 & 0,764 & 0,855 \\
\hline $\begin{array}{l}\text { Ông/Bà nghĩ rằng mình là khách hàng trung thành của } \\
\text { bệnh viện }\end{array}$ & TT2 & 6,474 & 0,751 & 0,860 \\
\hline $\begin{array}{l}\text { Ông/Bà sẽ tiếp tục sử dụng các dịch vụ khám bệnh, } \\
\text { chữa bệnh của bệnh viện }\end{array}$ & TT3 & 6,396 & 0,763 & 0,855 \\
\hline $\begin{array}{l}\text { Ông/Bà chỉ lựa chọn BV này khi có nhu cầu khám } \\
\text { chữa bệnh }\end{array}$ & TT4 & 6,445 & 0,750 & 0,860 \\
\hline
\end{tabular}

Nguồn: Tính toán của tác giả

\subsection{Phân tích nhân tố khám phá}

Trong bước phân tích nhân tố khám phá này tất cả 23 thang đo đảm bảo độ tin cậy đều được đưa vào phân tích, nghiên cứu sử dụng phương pháp rút trích Principal Axis Factoring cùng với phương pháp quay Promax. Kết quả phân tích nhân tố khám phá đối với nhóm thang đo hành vi đồng tạo sinh giá trị loại duy nhất thang đo TKTT4 vì không đảm bảo giá trị hội tụ. Kết quả phân tích cho thấy có 4 nhân tố được rút trích từ thang đo hành vi đồng tạo sinh giá trị là: hành vi có trách nhiệm (HVTN), hành vi giao tiếp (HVGT), hành vi tìm kiếm thông tin (TKTT) và hành vi chia sẻ thông tin (CSTT). Kết quả phân tích đối với thang đo sự hài lòng bệnh nhân (HL) và lòng trung thành bệnh nhân (TT) đều giử nguyên các thang đo ban đầu. Khi tiến hành phân tích thang đo tổng thể bao gồm tất cả các biến quan sát, nghiên cứu thu được kết quả là: hệ số KMO = 0.933 , kiểm định Barlett có ý nghĩa thống kê với sig. $=0.000$, và có 6 nhân tố được rút trích với trị số eigenvalue ở nhân tố thứ $6=1.055$ và tổng phương sai trích $=72.980 \%$. 


\section{Bảng 2}

Kết quả phân tích nhân tố khám phá thang đo tổng thể

Pattern Matrix ${ }^{a}$

\begin{tabular}{|c|c|c|c|c|c|c|}
\hline Biến quan sát & Nhân tố & & & & & \\
\hline & 1 & 2 & 3 & 4 & 5 & 6 \\
\hline HVTN1 & .872 & & & & & \\
\hline HVTN5 & .798 & & & & & \\
\hline HVTN4 & .696 & & & & & \\
\hline HVTN2 & .677 & & & & & \\
\hline HVTN3 & .631 & & & & & \\
\hline TT3 & & .879 & & & & \\
\hline TT1 & & .826 & & & & \\
\hline TT4 & & .779 & & & & \\
\hline TT2 & & .723 & & & & \\
\hline HL4 & & & .854 & & & \\
\hline HL1 & & & .823 & & & \\
\hline HL2 & & & .750 & & & \\
\hline HL3 & & & .666 & & & \\
\hline HVGT3 & & & & .872 & & \\
\hline HVGT2 & & & & .804 & & \\
\hline HVGT1 & & & & .786 & & \\
\hline TKTT1 & & & & & .852 & \\
\hline TKTT2 & & & & & .740 & \\
\hline TKTT3 & & & & & .713 & \\
\hline CSTT2 & & & & & & .869 \\
\hline CSTT1 & & & & & & .728 \\
\hline CSTT3 & & & & & & .715 \\
\hline
\end{tabular}

Nguồn: Tính toán của tác giả

\subsection{Phân tích nhân tố khẳng định}

Để tìm hiểu mối quan hệ giữa các yếu tố của hành vi đồng tạo sinh giá trị, sự hài lòng và lòng trung thành của bệnh nhân, trong hoạt động phân tích nhân tố khẳng định, mô hình được xây dựng gồm 6 biến tiềm ẩn. Kết quả CFA của thang đo có trọng số các biến quan sát đều đạt được chuẩn cho phép và có ý nghĩa thống kê với các giá trị $\mathrm{p}$ đều nhỏ hơn 0,05 . Như vậy các biến quan sát dùng để đo lường 6 thành phần của thang đo đạt được giá trị hội tụ. Kết quả CFA cho thấy mô hình có 194 bậc tự do, giá trị kiểm định chi-square $=200,096$ với $\mathrm{p}=0,367$, tuy nhiên chi-square/df 
$=1,031$ đạt yêu cầu < 2 và các chỉ số chỉ ra mô hình phù hợp với dữ liệu thị trường $(\mathrm{CFI}=0,999$, $\mathrm{TLI}=0,999$ và $\mathrm{RMSEA}=0,009$ ). Mô hình này đo lường phù hợp với dữ liệu và không có tương tác sai số đo lường nên nó đạt tính đơn nguyên.

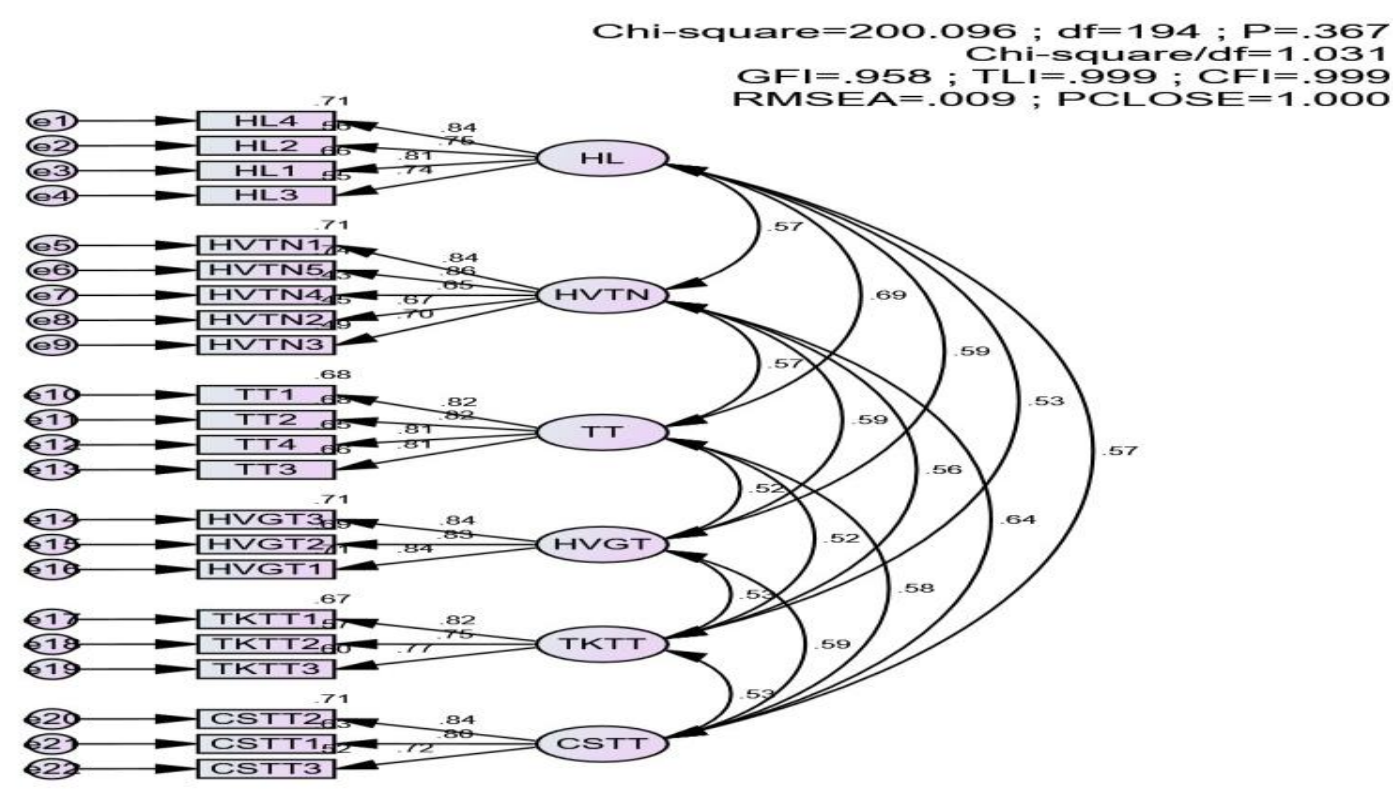

Hình 2. Kết quả phân tích nhân tố khẳng định (CFA)

Nguồn: Tính toán của tác giả

Tiếp theo, để phân tích mối quan hệ giữa hành vi đồng tạo sinh giá trị, sự hài lòng và lòng trung thành của bệnh nhân, ba cấu trúc chính được xây dựng trong mô hình là HVTG, HL và TT. Trong đó, hành vi đồng tạo sinh giá trị là cấu trúc bậc cao gồm bốn cấu trúc bậc thấp hơn là hành vi có trách nhiệm (HVTN), hành vi giao tiếp (HVGT), hành vi tìm kiếm thông tin (TKTT) và hành vi chia sẻ thông tin (CSTT). Kết quả cho thấy mô hình có bậc tự do $\mathrm{df}=202$, mô hình phù hợp với dữ liệu thị trường với các chỉ số đánh giá cụ thể: Chỉ tiêu Chi-square/df $=1,015<2$; $\mathrm{GFI}=0,956, \mathrm{TLI}=0,999, \mathrm{CFI}=0,999$ đều lớn hơn $0.9 ; \mathrm{RMSEA}=0,006<0,08$. Có thể khẳng định rằng mô hình là phù hợp với dữ liệu thu thập được. Bên cạnh đó, các chỉ số đo lường giá trị mô hình như $\mathrm{CR}, \mathrm{AVE}, \mathrm{MSV}$ đều có giá trị đạt yêu cầu giúp khẳng định thêm mô hình là đáng tin cậy.

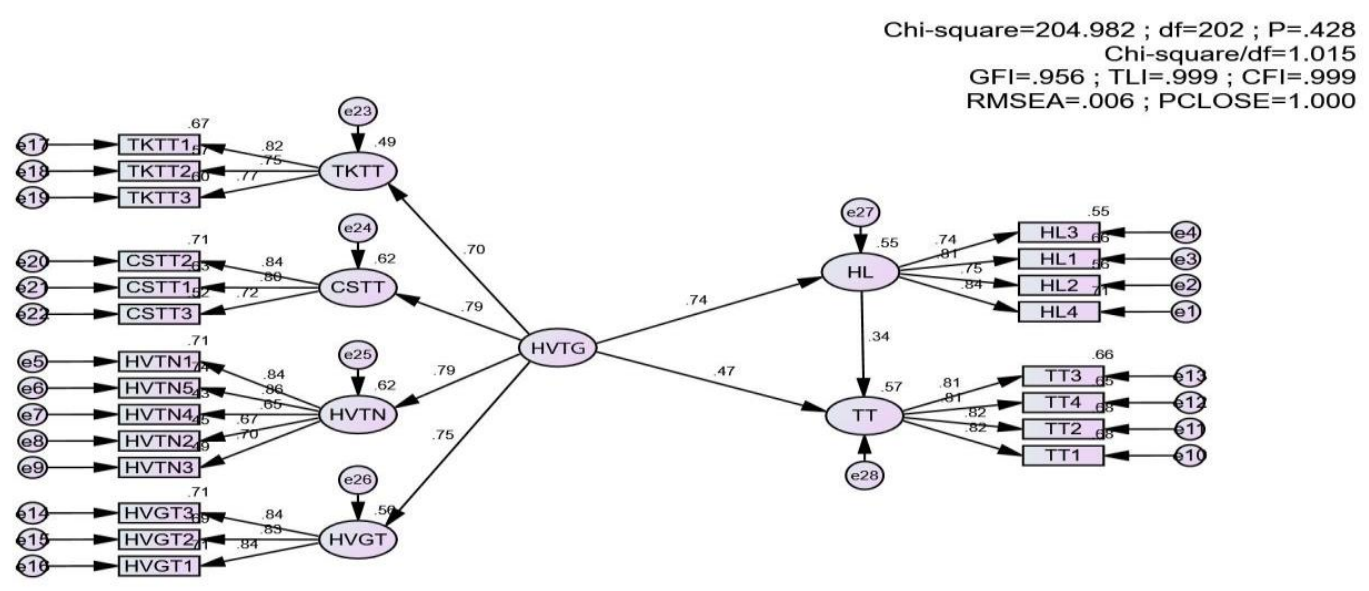

Hình 3. Kết quả phân tích mối quan hệ giữa hành vi đồng tạo sinh giá trị, sự hài lòng và lòng

Nguồn: Tính toán của tác giả trung thành của bệnh nhân 


\subsection{Kiểm mô hình phương trình cấu trúc (SEM)}

Căn cứ kết quả phân tích nhân tố khẳng định, phân tích mô hình phương trình cấu trúc được sử dụng để ước lượng mối quan hệ giữa: (i) các thành phần của hành vi đồng tạo sinh giá trị với sự hài lòng và lòng trung thành của bệnh nhân, và (ii) hành vi đồng tạo sinh giá trị tổng thể với sự hài lòng và lòng trung thành của bệnh nhân. Trước tiên, một mô hình giữa các cấu trúc: hành vi có trách nhiệm (HVTN), hành vi giao tiếp (HVGT), hành vi tìm kiếm thông tin (TKTT) và hành vi chia sẻ thông tin (CSTT) với sự hài lòng (HL) và lòng trung thành của bệnh nhân (TT) được xây dựng. Kết quả phân tích thu được giá trị các chỉ số đánh giá sự phù hợp của mô hình đều có giá trị đạt chuẩn giúp mô hình cấu trúc dưới đây được kết luận là phù hợp với bối cảnh nghiên cứu.

\section{Bảng 3}

Kết quả kiểm định mối quan hệ giữa các khái niệm của mô hình

\begin{tabular}{|c|c|c|c|c|c|c|}
\hline \multicolumn{3}{|c|}{ Mối quan hệ } & Giá trị ước & Sai lệch chuẩn & Giá trị tới hạn & Giá trị P- \\
\hline $\mathrm{HL}$ & $\leftarrow$ & HVTG & .683 & .051 & 13.504 & $* * *$ \\
\hline TKTT & $\leftarrow$ & HVTG & .612 & .050 & 12.217 & $* * *$ \\
\hline CSTT & $\leftarrow$ & HVTG & .685 & .048 & 14.231 & $* * *$ \\
\hline HVTN & $\leftarrow$ & HVTG & .721 & .049 & 14.635 & $* * *$ \\
\hline HVGT & $\leftarrow$ & HVTG & .653 & .048 & 13.729 & $* * *$ \\
\hline $\mathrm{TT}$ & $\leftarrow$ & HVTG & .365 & .062 & 5.866 & $* * *$ \\
\hline $\mathrm{TT}$ & $\leftarrow$ & $\mathrm{HL}$ & .287 & .065 & 4.382 & $* * *$ \\
\hline
\end{tabular}

Nguồn: Tính toán của tác giả

Qua kết quả kiểm định ở Bảng 3 cho thấy, 4 yếu tố cấu thành hành vi đồng tạo sinh giá trị là hành vi có trách nhiệm, hành vi chia sẻ thông tin, hành vi giao tiếp và hành vi tìm kiếm thông tin. Điều này cho thấy nghiên cứu của tác giả ủng hộ các kết quả nghiên cứu tìm được trước kia của Yi và Gong (2013), Revilla-Camacho và cộng sự (2015), H. N. Le (2016) và Huynh (2018). Đồng thời, kết quả kiểm định cũng khẳng định, hành vi đồng tạo sinh giá trị có ảnh hưởng tích cực đến sự hài lòng của bệnh nhân và lòng trung thành của bệnh nhân. Điều đó có nghĩa là, khi hành vi đồng tạo sinh giá trị càng cao thì sự hài lòng của bệnh nhân càng được cải thiện. Kết quả nghiên cứu này tương tự đã được kiểm chứng trong các nghiên cứu của Lee và cộng sự (2012) và Gallan và cộng sự (2013). Kết quả kiểm định cũng cho chúng ta biết được sự tác động tích cực của hành vi đồng tạo sinh giá trị đến lòng trung thành của bệnh nhân (Chen \& Wang, 2016; H. N. Le, 2016). Cuối cùng, kết quả kiểm định thể hiện sự hài lòng của bệnh nhân có ảnh hưởng tích cực đến lòng trung thành của bệnh nhân. Kết quả này ủng hộ kết quả của các nghiên cứu thực nghiệm khác như nghiên cứu của Platonova và cộng sự (2008), Friesner và cộng sự (2009), Tran (2014), H. T. M. Nguyen (2014) và Lam (2017).

\section{Kết luận và khuyến nghị}

Nghiên cứu mối quan hệ giữa hành vi đồng tạo sinh giá trị, sự hài lòng và lòng trung thành của khách hàng trong lĩnh vực y tế đã được thực hiện ở cấp độ tổng thể khi xem xét hành vi đồng tạo sinh giá trị ở khái niệm bậc cao và ở cấp độ thành phần. Nghiên cứu được tiến hành bằng cách 
phỏng vấn trực tiếp 405 bệnh nhân nội trú được xuất viện tại thời điểm phỏng vấn đồng ý tham gia tại các khoa của bệnh viện Quận Thủ Đức với phương pháp mô tả cắt ngang. Phỏng vấn bằng bộ câu hỏi được thiết kế sẵn trên nguyên tác kế thừa từ các nghiên cứu trước với 23 thang đo. Trong quá trình thực hiện, nghiên cứu đã sử dụng kết hợp phương pháp nghiên cứu định tính và phương pháp nghiên cứu định lượng. Phương pháp nghiên cứu định tính được áp dụng trong việc xây dựng thang đo các khái niệm và phương pháp nghiên cứu định lượng được áp dụng để ước lượng các mối quan hệ giữa các khái niệm. Thang đo hành vi đồng tạo sinh giá trị trong nghiên cứu này có 15 biến quan sát, đo lường bốn thành phần là hành vi có trách nhiệm, hành vi giao tiếp, hành vi tìm kiếm thông tin và hành vi chia sẻ thông tin. Thang đo sự hài lòng với 4 thang đo và lòng trung thành của bệnh nhân có 4 thang đo. Kết quả nghiên cứu xác định tất cả 4 thành phần của hành vi đồng tạo sinh giá trị (hành vi có trách nhiệm, hành vi giao tiếp, hành vi tìm kiếm thông tin và hành vi chia sẻ thông tin) và hành vi đồng tạo sinh giá trị tổng thể của bệnh nhân có mối quan hệ tích cực với sự hài lòng và lòng trung thành của bệnh nhân. Đồng thời, kết quả kiểm định cho thấy yếu tố sự hài lòng của bệnh nhân có mối quan hệ tích cực đến lòng trung thành của họ. Từ kết qủa nghiên cứu thu được, một số khuyến nghị đã được đề xuất.

Khi mà thông tin y tế ngày càng nhiều và có khắp mọi nơi, thì hành vi tìm kiếm thông tin của bệnh nhân đóng vai trò quan trọng hơn trong việc chăm sóc sức khoẻ cá nhân của họ và đây cũng là hoạt động có chủ đích của bệnh nhân. Để tạo điều kiện cho bệnh nhân tiếp cận được những thông tin y tế đầy đủ và chính xác nhất, thì bệnh viện cần phải xây dựng, mở rộng và quản lý các kênh truyền thông của mình. Tất cả những thông tin khi được thông báo với bệnh nhân đều phải được nghiên cứu chứng minh và đăng tải trên các trang điện tử uy tín như: trang điện tử bệnh viện, bản tin bệnh viện, báo chí y tế. Bên cạnh đó, tại các khu vực chờ đợi, bệnh viện cần bố trí thêm các quầy thông tin, thiết kế bảng thông báo về quy trình khám chữa bệnh và các thông tin cần thiết. Hành vi chia sẻ thông tin, là một hoạt động mà bệnh nhân chủ động cung cấp với nhân viên y tế về tình trạng bệnh tật cũng như sức khoẻ hàng ngày của mình. Đây là một hành động tốt nhằm giúp cho nhân viên y tế hiểu rõ ràng và kịp thời về tình trạng sức khoẻ của bệnh nhân. Mặt khác, việc chia sẻ thông tin này giúp cho họ tiết kiệm được thời gian đăng kí khám chữa bệnh. Vì vậy, nên áp dụng công nghệ thông tin vào việc đăng kí khám chữa bệnh trực tuyến, qua tổng đài sẽ giúp cho bệnh nhân tiết kiệm được thời gian chờ đợi tại bệnh viện, bên cạnh đó cũng giảm tình trạng quá tải tại các bệnh viện, đồng thời cũng giúp cho nhân viên y tế thu thập đầy đủ thông tin về tiền sử và bệnh sử của người đăng ký. Hiện nay, các chuyên gia y tế và y đức chú trọng trách nhiệm của bác sĩ hơn là trách nhiệm của bệnh nhân. Tuy nhiên, để đạt được một sức khoẻ tốt thì cần phải có sự phối hợp về trách nhiệm của bác sĩ và bệnh nhân. Do đó hành vi trách nhiệm của bệnh nhân là một hành động chủ động tương tác, tuân thủ theo quy trình điều trị và hướng dẫn của nhân viên y tế. Hành vi này có ý nghĩa rất lớn đối với kết quả điều trị, giúp kết quả điều trị được tốt hơn và rút ngắn thời gian nằm viện của bệnh nhân. Vì vậy, để tăng cường tần suất của hành vi có lợi này, bệnh viện cần có đội ngũ chăm sóc khách hàng hướng dẫn người bệnh một cách chi tiết về việc tuân thủ điều trị, đồng thời bộ phận thông tin phải sử dụng hệ thống tin nhắn tự động nhắc bệnh nhân tới khám định kỳ, đúng hẹn. Bên cạnh đó đơn vị Dược lâm sàng cần phải thể hiện đầy đủ thông tin về liều dùng, cách sử dụng và thông tin liên lạc trên toa thuốc. Hành vi cư xử lịch sự tử tế của nhân viên y tế dành cho bệnh nhân, đó cũng là một yếu tố quan trọng tác động đến lòng trung thành của bệnh nhân. Hiện nay, mô hình bệnh nhân là trung tâm trong việc điều trị bệnh đã được áp dụng trên tất cả các bệnh viện, vì vậy để làm cho người bệnh hài lòng cũng như là thái độ cư xử của đội ngũ $y$, bác sĩ đối với người bệnh là điều đáng được quan tâm. Chính vì vậy bệnh viện cần phải nâng cao chất lượng khám chữa bệnh, chăm sóc bệnh nhân cẩn thận, chu đáo. Bên cạnh đó, bệnh viện cần phải có những lớp đào tạo hướng dẫn nhân viên của mình về cách giao tiếp, đồng cảm với bệnh nhân nhằm tăng cường sự hài lòng của người bệnh đối với bệnh viện. 
Đồng thời nâng cao chất lượng chăm sóc, đổi mới phong cách, thái độ phục vụ của nhân viên y tế nhằm tạo lòng tin cho bệnh nhân. Tiếp đến cũng thay đổi được cách nhìn của bệnh nhân đối với cán bộ ngành y tế.

Cuối cùng, nghiên cứu cũng có một số hạn chế. Nghiên cứu này chỉ thực hiện tại bệnh viện Quận Thủ Đức. Khả năng tổng quát hóa kết quả của nghiên cứu sẽ cao hơn nếu nó được thực hiện tiếp tại một số bệnh viện của thành phố khác nữa tại Việt Nam. Đồng thời mở rộng thêm đối tượng nghiên cứu là ngoại trú và nội trú. Đây là một hướng cho các nghiên cứu trong tương lai. Vì đây là một nghiên cứu tương đối mới tại Việt Nam, khi xây dựng mô hình nghiên cứu tác giả đa phần dựa vào các nghiên cứu nước ngoài. Nguồn tài liệu tham khảo còn hạn chế. Ngoài ra, hạn chế của nghiên cứu chỉ chú trọng ảnh hưởng của hành vi tham gia (hành vi đồng tạo giá trị) và sự hài lòng tác động đến lòng trung thành của bệnh nhân qua dữ liệu cắt ngang (cross-sectional data) nếu thu thập dữ liệu qua các giai đoạn thời gian khác nhau sẽ đảm bảo tính logic hơn của mô hình nhân quả. Cuối cùng, có thể có nhiều yếu tố khác nữa góp phần vào việc giải thích cho sự hài lòng và lòng trung thành của bệnh nhân như các yếu tố về đặc điểm cá nhân, yếu tố tạo sự thân thiện cho người bệnh khi đến bệnh viện. Đây cũng là một chủ đề cho hướng nghiên cứu sau này.

\section{LỜI CÁM ƠN}

- Nghiên cứu này được Trường Đại học Quốc tế, ĐHQG-HCM tài trợ trong đề tài có mã số T201901-BA.

- Cám ơn cơ quan phối hợp thực hiện: Bệnh viện Quận Thủ Đức.

\section{Tài liệu tham khảo}

Allegranzi, B., Storr, J., Dziekan, G., Leotsakos, A., Donaldson, L., \& Pittet, D. (2007). The first global patient safety challenge "clean care is safer care": From launch to current progress and achievements. Journal of Hospital Infection, 65(2), 115-123.

Astuti, H. J., \& Nagase, K. (2016). A framework for conceptualizing patient loyalty to healthcare organizations. Health Services Management Research, 29(3), 70-78.

Bitner, M. J. (1990). Evaluating service encounters: The effects of physical surroundings and employee responses. Journal of Marketing, 54(2), 69-82.

Bitner, J. M., Faranda, T. W., Hubbert, R. A., \& Zeithaml, A. V. (1997). Customer contributions and roles in service delivery. International Journal of Service Industry Management, 8(3), 193-205.

Bottorff, J. L., Steele, R., Davies, B., Garossino, C., Porterfield, P., \& Shaw, M. (1998). Striving for balance: Palliative care patients' experiences of making everyday choices. Journal of Palliative Care, 14(1), 7-17.

Carrubbo, L., Bruni, R., Cavacece, Y., \& Tartaglione, A. (2015). Service system platforms to improve value co-creation: Insights for translational medicine. Paper presented at the 2015 Naples Forum on Service, Naples.

Cossío-Silva, F.-J., Revilla-Camacho, M. Á., Vega-Vázquez, M., \& Palacios-Florencio, B. (2016). Value co-creation and customer loyalty. Journal of Business Research, 69(5), 1621-1625.

Chahal, H. (2008). Predicting patient loyalty and service quality relationship: A case study of civil hospital, Ahmedabad, India. Vision - The Journal of Business Perspective, 12(4), 45-55. 
Chen, C., \& Wang, J. (2016). Customer participation, value co-creation and customer loyalty - A case of airline online check-in system. Computers in Human Behavior, 62, 346-352.

Chuang, H., \& Chen, Y. (2015). Identifying the value co-creation behavior of virtual customer environments using a hybrid expert-based DANP model in the bicycle industry. Humancentric Computing and Information Sciences, 5(1), 1-31.

Delpechitre, D., Connelly, L., \& Chaker, N. (2018). Customer value co-creation behavior: A dyadic exploration of the influence of salesperson emotional intelligence on customer participation and citizenship behavior. Journal of Business Research, 92, 9-24.

Eldh, A. C., Ekman, I., \& Ehnfors, M. (2006). Conditions for patient participation and nonparticipation in health care. Nursing Ethics, 13(5), 503-514.

Ennew, C. T., \& Binks, M. R. (1996). The impact of service quality and service characteristics on customer retention: Small businesses and their banks in the UK. British Journal of Management, 7(3), 219-30.

Ennew, C. T., \& Binks, M. R. (1999). Impact of participative service relationships on quality, satisfaction and retention: An exploratory study. Journal of Business Research, 46(2), 121-32.

Fornell, C. (1992). A national customer satisfaction barometer: The Swedish experience. Journal of Marketing, 56(1), 6-21.

Fornell, C., Johnson, M. D., Anderson, E. W., Cha, J., \& Bryant, B. E. (1996). The American customer satisfaction index: Nature, purpose, and findings. Journal of Marketing, 60(4), 7-18.

Friesner, D., Neufelder, D., Raisor, J., \& Bozman, C. S. (2009). How to improve patient satisfaction when patients are already satisfied: A continuous process-improvement approach. Hospital Topics, 87(1), 24-40.

Gallan, A. S., Jarvis, C. B., Brown, S. W., \& Bitner, M. J. (2013). Customer positivity and participation in services: An empirical test in a health care context. Journal of the Academy of Marketing Science, 41(3), 338-356.

Gotlieb, J. B., Grewal, D., \& Brown, S. W. (1994). Consumer satisfaction and perceived quality: Complementary or divergent constructs? Journal of Applied Psychology, 79(6), 875-885.

Grönroos, C., \& Voima, P. (2013). Critical service logic: Making sense of value creation and cocreation. Journal of the Academy of Marketing Science, 41(2), 133-150.

Gronholdt, L., Martensen, A., \& Kristensen, K. (2000). The relationship between customer satisfaction and loyalty: Cross-industry differences. Total Quality Management, 11, 509-514.

Hansemark, O. C., \& Albinsson, M. (2004). Customer satisfaction and retention: The experiences of individual employees. Managing Service Quality: An International Journal, 14(1), 40-57.

Huynh, T. D. T. (2018). Mối quan hệ giữa hành vi đồng tạo giá trị, sự hài lòng, lòng trung thành của người bệnh tại các bệnh viện công lập tuyến quận, huyện trên địa bàn Thành phố Hồ Chi Minh [The relationship between the co-value, satisfaction, and loyalty of patients in public hospitals at the district level in Ho Chi Minh City] (Master's thesis, University of Economics Ho Chi Minh City, Vietnam). Retrieved October 20, 2018, from http://digital.lib.ueh.edu.vn/handle/UEH/57937 
Lam, N. Q. (2017). Chất lương dịch vu, sự hài lòng và lòng trung thành của ngườ bệnh ngoại trú tại các cơ sở khám chũa bệnh đa khoa tu nhân trên địa bàn thành phố Hồ Chí Minh [Service quality, satisfaction and loyalty of outpatients at private general clinics in Ho Chi Minh City] (Master's thesis, University of Economics Ho Chi Minh City, Vietnam). Retrieved October 25, 2018, from http://digital.lib.ueh.edu.vn/handle/UEH/56945

Le, H. N. (2016). Đồng tạo sinh giá trị trong lĩnh vục dịch vu thâm dụng tri thức - nghiên cúu trong hai lĩnh vục giáo dục đại học và dịch vu y tế [Co-generation of value in knowledgeintensive services - research in two areas of higher education and medical services]. Ho Chi Minh, Vietnam: Đại học Quốc Gia TPHCM.

Le, T. T. (2017). Các nhân tố ảnh hưởng đến mức độ hài lòng của ngườ bệnh nội trú đối với chất lương khám, chũa bệnh tại Bệnh viện đa khoa Thị xã Duyên Hải, Tỉnh Trà Vinh [Factors affecting the satisfaction of inpatients with respect to medical examination and treatment quality at Duyen Hai Town General Hospital, Tra Vinh Province] (Master's thesis, University of Economics Ho Chi Minh City, Vietnam). Retrieved October 26, 2018, from http://digital.lib.ueh.edu.vn/handle/UEH/54574

Lee, D. (2017). A model for designing healthcare service based on the patient experience. International Journal of Healthcare Management, 12(3), 180-188.

Lee, S. M., Lee, D., \& Kang, C. (2012). The impact of high performance work systems in the health-care industry: Employee reactions, service quality, customer satisfaction, and customer loyalty. The Service Industries Journal, 32(1), 17-36.

Mohan, R., \& Kumar, K. S. (2011). A study on the satisfaction of patients with reference to hospital services. Zenith International Journal of Business Economics \& Management Research, 1(3), 15-25.

Nguyen, H. T. M. (2014). Nghiên cưu các yếu tố ảnh hương đến sụ hài lòng và lòng trung thành của khách hàng đối với dịch vụ nha khoa tại phòng khám nha khoa trên địa bàn TP. HCM [Research on factors affecting customer satisfaction and loyalty to dental services at dental clinics in HCM City] (Master's thesis). University of Economics Ho Chi Minh City, Vietnam).

Nguyen, T. D., \& Nguyen, T. T. M. (2011). Nghiên cưu khoa học Marketing ứng dụng mô hình cấu trúc tuyến tính SEM [Marketing science research applying SEM linear structure model]. Ho Chi Minh, Vietnam: Nhà Xuất bản Lao Động.

Platonova, E. A., Kennedy, K. N., \& Shewchuk, R. M. (2008). Understanding patient satisfaction, trust, and loyalty to primary care physicians. Medical Care Research and Review, 65(6), 696-712.

Rafii, F., Soleimani, M., \& Seyed-Fatemi, N. (2010). Concept analysis of participation of patient with chronic disease: Use of hybrid model. Iran Journal of Nursing, 23(67), 35-48.

Reichheld, F. F., \& Sasser, W. E. (1990). Zero defecfions: Quality comes to services. Harvard Business Review, 68(5), 105-111.

Revilla-Camacho, M., Vega-Vázquez, M., \& Cossío-Silva, F. J. (2015). Customer participation and citizenship behavior effects on turnover intention. Journal of Business Research, 68(7), 1607-1611.

Roser, T., Samson, A., Humphreys, P., \& Cruz-Valdivieso, E. (2009). Co-creation: New pathways to value an overview. London, UK: Promise. 
Singh, J. (1989). The patient satisfaction concept: A review and reconceptualization. Advances in Consumer Research, 16, 176-179.

Sweeney, J., Danaher, T., \& McColl-Kennedy, J. (2015). Customer effort in value co-creation activities: Improving quality of life and behavioral intentions of health care customers. Journal of Service Research, 18(3), 318-335.

Tommasetti, A., Troisi, O., \& Vesci, M. (2017). Measuring customer value co-creation behavior: Developing a conceptual model based on service-dominant logic. Journal of Service Theory and Practice, 27(5), 930-950.

Tutton, E. M. M. (2005). Patient participation on a ward for frail older people. Journal of Advanced Nursing, 50(2), 143-152.

Thompson, A. G. H. (2007). The meaning of patient involvement and participation in health care consultations: A taxonomy. Social Science \& Medicine, 64(6), 1297-1310.

Tran, H. C. (2014). Anh hương của giá trị cảm nhận đến sụ hài lòng và lòng trung thành của khách hàng đối với dịch vụ khám chũa bệnh: Nghiên cưu truờng hợp các bệnh viện tu nhân tại TP. Hồ Chí Minh [Influence of perceived value on customer satisfaction and loyalty to medical services: A case study of private hospitals in Ho Chi Minh city] (Master's thesis). University of Economics Ho Chi Minh City, Vietnam.

Vargo, S., \& Lusch, R. (2008). Service-dominant logic: Continuing the evolution. Journal of the Academy of Marketing Science, 36(1), 1-10.

Vega-Vazquez, M., Revilla-Camacho, M., \& Cossío-Silva, F. (2013). The value co-creation process as a determinant of customer satisfaction. Management Decision, 51(10), 19451953.

Weisheng, C., Doyeon, W., \& Jung-sup, B. (2019). Customer value co-creation behaviour in fitness centres: How does it influence customers' value, satisfaction, and repatronage intention? Managing Sport and Leisure, 24(1/3), 32-44.

Yi, Y., \& Gong, T. (2013). Customer value co-creation behavior: Scale development and validation. Journal of Business Research, 66(9), 1279-1284.

Zyzanski, S. J., Hulka, B. S., \& Cassel, J. C. (1974). Scale for the measurement of "satisfaction" with medical care: Modifications in content, format and scoring. Medical Care, 12(7), 611-620. 